\title{
Crescimento e fotossíntese de dois materiais genéticos do coqueiro submetidos a desfolha artificial
}

As mudas do coqueiro podem ser atacadas por várias espécies de insetos, especialmente no viveiro por lagartas desfolhadoras como Opsiphanes invirae, que reduzem o crescimento e aumentam os custos de produção. Objetivou-se avaliar os efeitos causados pelo desfolhamento artificial, através dos parâmetros morfofisiológicos em mudas do coqueiro em simulação ao ataque das lagartas de $\mathrm{O}$. invirae. Foram avaliados dois materiais genéticos: Híbrido PB121 e anão verde do Brasil em quatro níveis de desfolha: T0 (tratamento controle), sem desfolhamento; T30 (30\% de desfolha); T60 (60\% de desfolha) e T90 ( $90 \%$ de desfolha) Foram medidos taxa de assimilação líquida de $\mathrm{CO} 2(\mathrm{~A})$, condutância estomática (gs), taxa de transpiração (E) e relação carbono intercelular e carbono atmosférico $(\mathrm{Ci} / \mathrm{Ca})$, além de área foliar, altura, diâmetro do coleto, massa seca e índice de robustez. Os resultados demonstraram que mudas do coqueiro anão verde do Brasil apresentaram maiores médias para gs, E e Ci/Ca. O tratamento T90 apresentou redução de 17,56\% na taxa de assimilação líquida de CO2 (A) comparado ao T0. Por outro lado, o material genético híbrido PB121 apresentou as maiores médias para área foliar, altura, diâmetro do coleto e matéria seca da parte aérea. Não houve interação significativa entre os materiais genéticos e níveis de desfolha (MGXD). Mudas do híbrido PB121 com 30\% de desfolha (T30) foram capazes recuperar a área foliar perdida, igualando-se ao tratamento controle (TO). Esse nível de desfolhamento equivale ao consumo de 3 lagartas desfolhadoras/planta, sendo o indicativo biológico para tomadas de decisão de controle no viveiro.

Palavras-chave: Trocas Gasosas; Lagarta Desfolhadora; Compensação de Crescimento.

\section{Growth and photosynthesis of two genetic materials from coconut palm submitted to artificial defoliation}

\begin{abstract}
The Coconut palm seedlings can be attacked by various insect species, especially in the nursery by leaf cutters caterpillars like Opsiphanes invirae, which reduce growth and increase production costs. The objective was to evaluate the effects caused by artificial defoliation, through the morphophysiological parameters in coconut tree seedlings simulated to the attack of O. invirae caterpillars. Two genetic materials were evaluated: Hybrid PB121 and Brazilian green dwarf at four defoliation levels: T0 (control treatment), without defoliation; T30 (30\% defoliation); T60 (60\% defoliation) and T90 (90\% defoliation). Were measured net CO2 assimilation rate (A), stomatal conductance (gs), perspiration rate (E), and intercellular carbon and atmospheric carbon (Ci / Ca), in addition to leaf area, height, stem diameter, dry mass and robustness index. The demonstrated results that seedilings of green dwarf coconut tree in Brazil show higher averages for gs, $\mathrm{E}$ and $\mathrm{Ci} / \mathrm{Ca}$. The Treatment T90 showed a $17.56 \%$ reduction in the rate of net $\mathrm{CO} 2$ assimilation (A) compared to T0. On the other hand, the hybrid genetic material PB121 has the largest media for leaf area, height, stem diameter and dry matter of the area. There was no significant interaction between genetic materials and defoliation levels (MGXD). Seedlings of PB121 hybrid with 30\% defoliation (T30) were able to recover the lost leaf area, equaling the control treatment (T0). This level of defoliation is equivalent to the consumption of 3 leaf/plants cutters caterpillars, being the biological indicator for control decision making in the nursery.
\end{abstract}

Keywords: Gas Exchange; Leaf Cutters Caterpillar; Growth Compensation.

Topic: Proteção de Plantas e Fitotecnia

Reviewed anonymously in the process of blind peer
Received: 04/12/2019

Approved: 10/01/2020
Ana Carolina Cavalcante Jucá (iD

Universidade Federal Rural da Amazônia, Brasil http://lattes.cnpq.br/0100083959688931 http://orcid.org/0000-0001-6722-1850 caroljuca21@gmail.com

Gledson Luiz Salgado de Castro (D)

Universidade Federal Rural da Amazônia, Brasil http://lattes.cnpq.br/7980739792448566 http://orcid.org/0000-0002-3126-6720 gledsoncastro87@gmail.com

\section{Denis de Pinho Sousa}

Universidade Federal Rural da Amazônia, Brasil http://lattes.cnpq.br/1268581733812720 http://orcid.org/0000-0001-5300-6383 denisdepinho@agronomo.eng.br
Susana Silva Conceição (iD)

Universidade Federal do Ceará, Brasil http://lattes.cnpq.br/7024508066767442 http://orcid.org/0000-0003-3625-3838 su tseliot@yahoo.com.br

\section{Rafael Coelho Ribeiro}

Universidade Federal do Pará, Brasil

http://lattes.cnpq.br/1890144400836608 rribeiro@ufpa.br

Paulo Manoel Pontes Lins (iD)

Sococo, Brasil

http://orcid.org/0000-0002-6452-9363

paulom@sococo.com.br

\section{Lana Letícia Barbosa de Carvalho \\ Universidade Federal Rural da Amazônia, Brasil http://lattes.cnpq.br/3918313011391120} lana agro2012@hotmail.com

Telma Fátima Vieira Batista

Universidade Federal Rural da Amazônia, Brasil http://lattes.cnpq.br/8251281115341075 telmabatistacoelho@yahoo.com.br

\section{Referencing this:}

JUCÁ, A. C. C.; CASTRO, G. L. S.; SOUSA, D. P.; CONCEIÇÃO, S. S.; RIBEIRO, R. C.; LINS, P. M. P.; CARVALHO, L. L. B.; CARVALHO, L. L. B.; BATISTA, T. F. V.. Crescimento e fotossíntese de dois materiais genéticos do coqueiro submetidos a desfolha artificial. Revista lbero Americana de Ciências Ambientais, v.11, n.1, p.63-71, 2020. DOI: http://doi.org/10.6008/CBPC2179-6858.2020.001.0007 


\section{INTRODUÇÃO}

O coqueiro possui origem no sudeste do continente asiático, onde se localizam os países com a maior produção mundial (FONTES, 2010). Existem duas variedades de coqueiro: Anão e gigante, no entanto há cruzamentos intervarietais que surgiram com o objetivo de reunir características desejáveis das duas variedades em um único individuo, são denominados híbridos (LOIOLA et al., 2005).

Os insetos podem afetar a cadeia produtiva do coqueiro (FERREIRA et al., 2015), e os desfolhadores são um dos mais importantes problemas fitossanitários, capazes de comprometer a produtividade em todas as fases de desenvolvimento, bem como, a qualidade final do produto propiciando elevados danos econômicos aos produtores (JUHÁSZ et al., 2013). Os insetos desfolhadores têm como maior dano a redução da área foliar, comprometendo, assim, a capacidade fotossintética da planta. Em condições de grandes infestações, o desfolhamento se torna fator limitante ao pleno crescimento da planta (CANTARELLI et al., 2008).

Destacam-se as espécies Opsiphanes invirae (Lepidoptera: Nymphalidae) e Synale hylaspes (Lepidoptera: Hesperiidae), as quais, em ataques intensos, são capazes de desfolhar por completo a planta, destruindo todo o limbo foliar a partir da borda, deixando apenas a nervura central de plantas adultas (FERREIRA, 2008). O baixo investimento em incremento de árvores desfolhadas pode ser determinado em comparação com árvores livres de dano (tratamento controle), quando cultivadas sob as mesmas condições (KULMAN, 1971).

Estudos relacionados à desfolha artificial produzem informações básicas e técnicas seguras que possibilitam o conhecimento quantitativo a respeito da capacidade das culturas tolerarem perdas de área foliar (FAZOLIN et al., 2004). Essa metodologia permite mensurar seguramente quanto de desfolha a cultura pode suportar em determinado estádio fenológico, quantificando a perda de produtividade em diferentes níveis de desfolha (LIMA JUNIOR et al., 2010). Visando contribuir para o desenvolvimento da cultura, objetivou-se avaliar os efeitos de diferentes níveis de desfolhamento artifical em mudas de coqueiro, em simulação ao causado pelo principal desfolhador, a lagarta $O$. invirae, através da avaliação morfológica e dos parâmetros de trocas gasosas.

\section{MATERIAIS E MÉTODOS}

O experimento foi realizado em casa de vegetação com temperatura média de $26^{\circ} \mathrm{C}$, umidade relativa

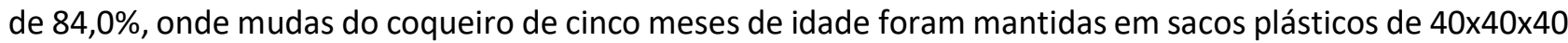
$\mathrm{cm}$, com substrato de fibra de coco. As mudas receberam adubação de ureia $(45 \% \mathrm{~N})$, superfosfato simples $\left(18 \% \mathrm{P}_{2} \mathrm{O}_{5}\right)$, cloreto de potássio $\left(60 \% \mathrm{~K}_{2} \mathrm{O}\right)$ e óxido de magnésio $(30 \% \mathrm{Mg})$, além de bórax $(10 \% \mathrm{~B})$, como recomendado por Lins et al. (2008). Sendo irrigadas, diariamente para repor a água perdida por evapotranspiração.

O experimento foi constituído por dois materiais genéticos: Híbrido PB121 (anão amarelo da Malásia $x$ gigante do oeste africano) e a variedade anão verde do Brasil. Em delineamento inteiramente ao acaso em 
esquema fatorial $2 \times 4$ e cinco repetições. Os níveis de desfolha foram determinados pela área foliar, onde se utilizou equações que relacionaram a área de folhas individuais com duas dimensões lineares (comprimento e largura), conforme metodologia proposta por Monteiro et al. (2005). Os níveis de desfolha adotados foram: T0 (Controle sem desfolha), T30, T60 e T90\% de desfolhamento.

As medições de trocas gasosas foram realizadas através do sistema portátil de fluxo aberto LI6400XT, (LI-COR, Lincoln, NE), sob concentração externa de $\mathrm{CO}_{2}$ de $400 \mu \mathrm{mol}^{-1}$ de ar e luz PAR artificial de $1.000 \mu \mathrm{mol}$ de fótons $\mathrm{m}^{-2} \mathrm{~s}^{-1}$, na porção intermediária da segunda folha expandida a partir do ápice da planta, no intervalo de $9 \mathrm{~h}: 00 \mathrm{~min}$ às $11 \mathrm{~h}: 00 \mathrm{~min}$, previamente determinado pela curva diurna de trocas gasosas. Mudas de cinco meses de idade foram avaliadas 40 dias após a imposição dos tratamentos, foram medidos os seguintes parâmetros: Taxa de assimilação líquida de $\mathrm{CO}_{2}(A)$, condutância estomática ( $\left.g s\right)$, taxa de transpiração $(E)$ e relação carbono intercelular e carbono atmosférico $(\mathrm{Ci} / \mathrm{Ca})$, além de área foliar, altura, diâmetro do coleto, matéria seca da parte aérea e da raiz e índice de robustez.

Os dados foram submetidos a análise de variância. Quando significativo, as médias foram comparadas pelo teste SNK (Student-Newman-Keuls) a 5\% de probabilidade no software R (versão 3.1.2 para Windows). Os dados de transpiração e massa seca da raiz foram submetidos à transformação em raiz quadrada. Realizou-se análise de regressão para efeito significativo das variáveis quantitativas.

\section{RESULTADOS}

Neste estudo, foram analisados 4 níveis de desfolhamento em diferentes percentuais (T0, T30, T60 e T90\%) em dois materiais genéticos de coqueiro: o híbrido PB121 e a variedade anão verde do Brasil se tomando como base, as alterações nas variáveis fisiológicas de trocas gasosas e biométricas quarenta dias após a desfolha. Os genótipos do coqueiro analisados apresentaram diferenças $(p>0,05)$ para a maioria dos parâmetros de crescimento (Tabela 1).

Tabela 1: Análise de variância dos dados de área foliar, altura, diâmetro do coleto, matéria seca da parte aérea, matéria seca da raiz e índice de qualidade de Dickson (IQD) dos materiais genéticos híbrido PB121 e anão verde do Brasil, em casa de vegetação.

\begin{tabular}{|c|c|c|c|c|c|c|}
\hline \multirow[t]{2}{*}{ FV } & \multicolumn{6}{|c|}{ Quadrado médio } \\
\hline & $\mathrm{AF}$ & Altura & Diâmetro do coleto & Parte aérea & Raiz & IQD \\
\hline M. genético (MG) & $2.917 .365,76^{*}$ & $2.924,10^{*}$ & $296,2^{*}$ & $594,37 *$ & 723,3 & 0,03 \\
\hline Desfolha (D) & $2.194 .151,21^{*}$ & 207,26 & 47,59 & $3.993,89 *$ & 359,64 & 0,17 \\
\hline$M G x D$ & $98.122,95$ & 116,66 & 6,184 & 113,53 & 91,42 & 0,19 \\
\hline Resíduos & 176551,51 & 139,35 & 21,09 & 129,82 & 18,07 & 0,11 \\
\hline CV (\%) & 13,65 & 8,19 & 10,74 & 3,42 & 14,98 & 10,12 \\
\hline
\end{tabular}

* Significante para $\mathrm{P}<0.05$.

O coqueiro híbrido PB121 apresentou os maiores incrementos na área foliar (AF), altura (H), diâmetro do coleto (DC) e na matéria seca da parte aérea (MSPA), com os respectivos valores de $3349 \mathrm{~cm}^{2}$, $153 \mathrm{~cm}^{2}, 46 \mathrm{~cm}^{2}, 337 \mathrm{~cm}^{2}$, estes resultados foram $16 \%, 11 \%, 12 \%, 2,3 \%$ superiores concomitantemente àqueles observados para o genótipo anão verde do Brasil (Figura 1). 

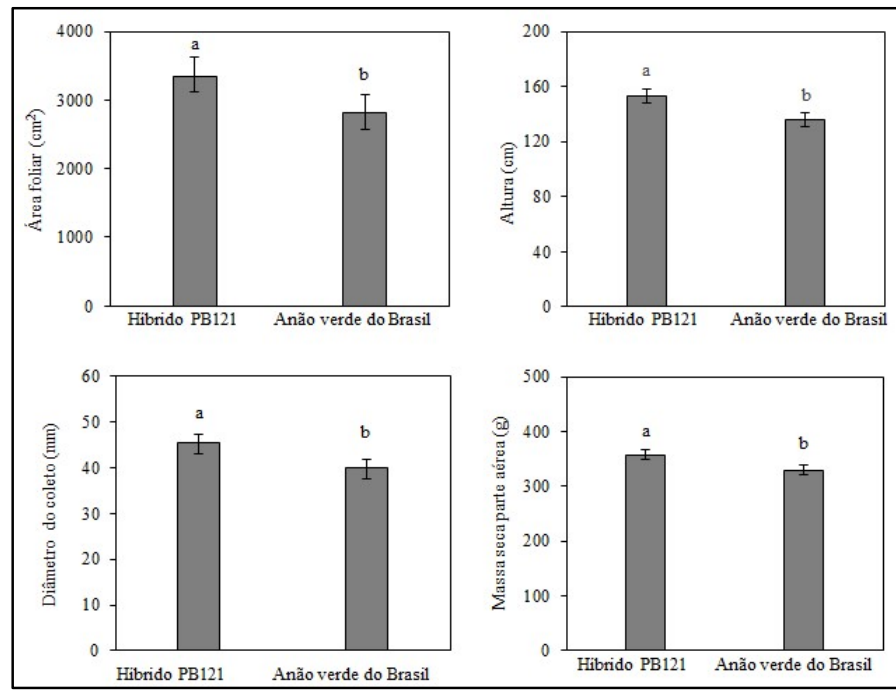

Figura 1: Altura, diâmetro do coleto, massa seca da parte aérea e área foliar dos materiais genéticos híbrido PB121 e anão verde do Brasil, em casa de vegetação. Médias com a mesma letra não diferem entre si pelo teste Student- Newman- Keuls a $5 \%$ de probabilidade.

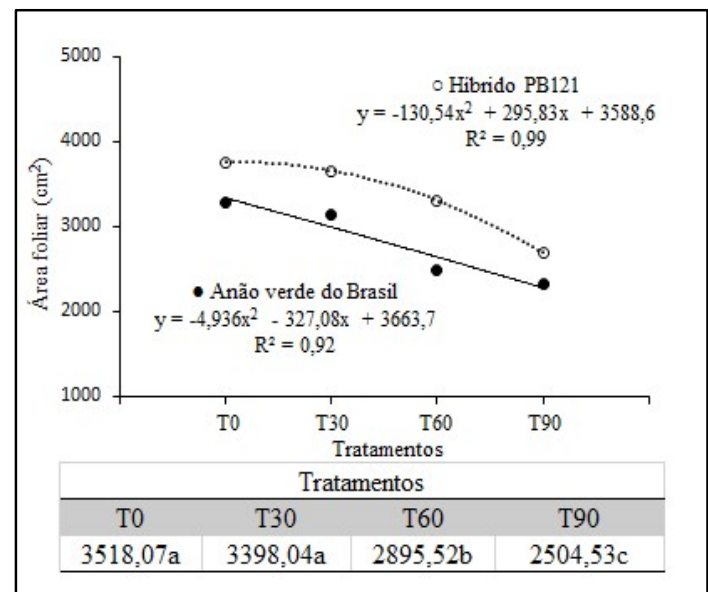

Figura 2: Análise de regressão da área foliar dos materiais genéticos híbrido PB121 e anão verde do Brasil, em quatro níveis de desfolha com suas funções de regressão e respectivas médias.

Médias com a mesma letra não diferem entre si pelo teste Student- Newman- Keuls a $5 \%$ de probabilidade.

Os menores valores para AF e para MSPA foram obtidos com os tratamentos T60 e T90 para ambos os materiais genéticos estudados (Figura 2 e 3). Por outro lado, não houve diferença significativa $(p>0,05)$ entre os tratamentos T0 e T30 para àquelas variáveis.

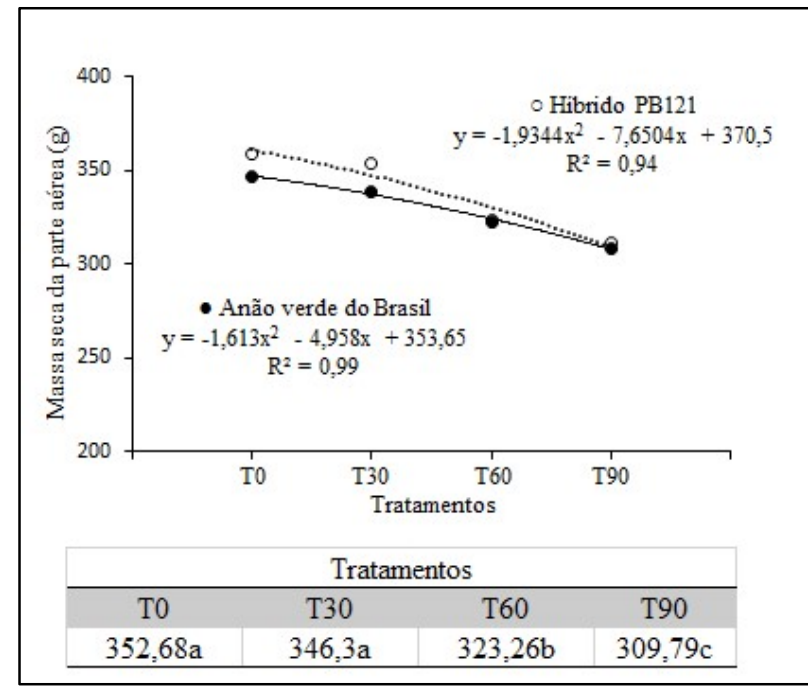

Figura 3: Análise de regressão da massa seca dos materiais genéticos híbrido PB121 e anão verde do Brasil, em quatro níveis de desfolha com suas funções de regressão e respectivas médias. Médias com a mesma letra não diferem entre si pelo teste StudentNewman- Keuls a $5 \%$ de probabilidade.

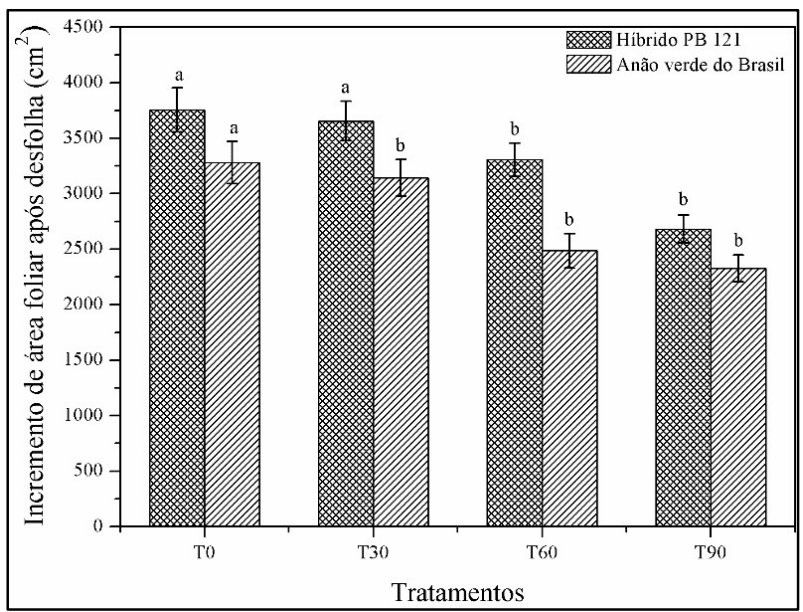

Figura 4: Incremento de área foliar de mudas do coqueiro do híbrido PB121 e anão verde do Brasil, em casa de vegetação. Médias com a mesma letra não diferem entre si pelo teste Student- Newman- Keuls a $5 \%$ de probabilidade.

Sob efeito do tratamento T30, mudas do híbrido PB121 exibiram recuperação da produção de biomassa vegetal, emitindo $4.000 \mathrm{~cm}^{2}$ de área foliar. Nesta condição, a AF do genótipo PB121 foi 200\% superior à das mudas do coqueiro anão verde do Brasil o que foi paralelamente acompanhada pela emissão folhas novas, similarmente ao observado nas plantas controle (Figura 4). Não houve recuperação da AF para 
as mudas do coqueiro anão verde do Brasil e, desta forma, não atingiu o padrão comercial. A análise de variância de trocas gasosas mostra diferenças entre os materiais genéticos estudados. (Tabela 2).

Tabela 2: Análise de variância da taxa de assimilação líquida de $\mathrm{CO}_{2}(\mathrm{~A})$, condutância estomática (gs), taxa de transpiração $(\mathrm{E})$ e relação carbono intercelular e carbono atmosférico $(\mathrm{Ci} / \mathrm{Ca})$ dos materiais genéticos híbrido PB121 e anão verde do Brasil, em casa de vegetação.

\begin{tabular}{|c|c|c|c|c|}
\hline FV & Quadrad & & & \\
\hline & $A$ & gs & $E$ & $\mathrm{Ci} / \mathrm{Ca}$ \\
\hline Material genético (MG) & 3,560 & $0,0045^{*}$ & $1,588^{*}$ & $0,010^{*}$ \\
\hline Desfolha (D) & $14,140 *$ & 0,0002 & 0,189 & 0,006 \\
\hline$M G \times D$ & 2,756 & 0,0005 & 0,402 & 0,004 \\
\hline Resíduos & 1,610 & 0,0003 & 0,190 & 0,002 \\
\hline CV (\%) & 10,67 & 13,98 & 10,04 & 8,04 \\
\hline
\end{tabular}

As trocas gasosas apresentaram maiores incrementos na variedade anão verde do Brasil para as variáveis de condutância estomática $(g s)$, transpiração $(E)$ e relação $(C i / C a)$ sendo, respectivamente, 13\%, $8 \%$ e 5\%, superiores àqueles observados no híbrido PB121 (Figura 5).

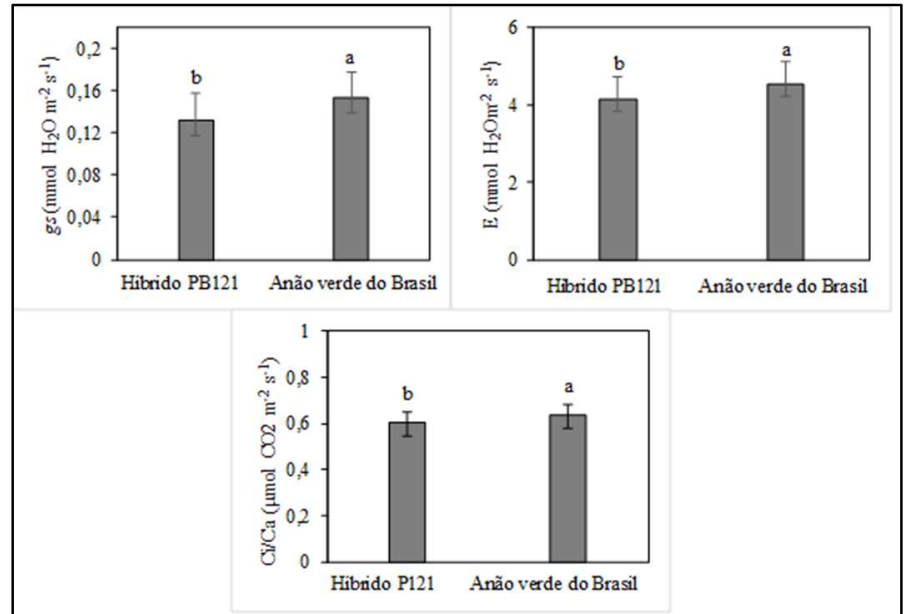

Figura 5: Condutância estomática (gs), taxa de transpiração (E) e relação carbono intercelular e carbono atmosférico (Ci/Ca) em mudas do coqueiro híbrido PB121 e anão verde do Brasil, em casa de vegetação. Médias com a mesma letra não diferem entre si pelo teste Student- Newman- Keuls a 5\% de probabilidade.

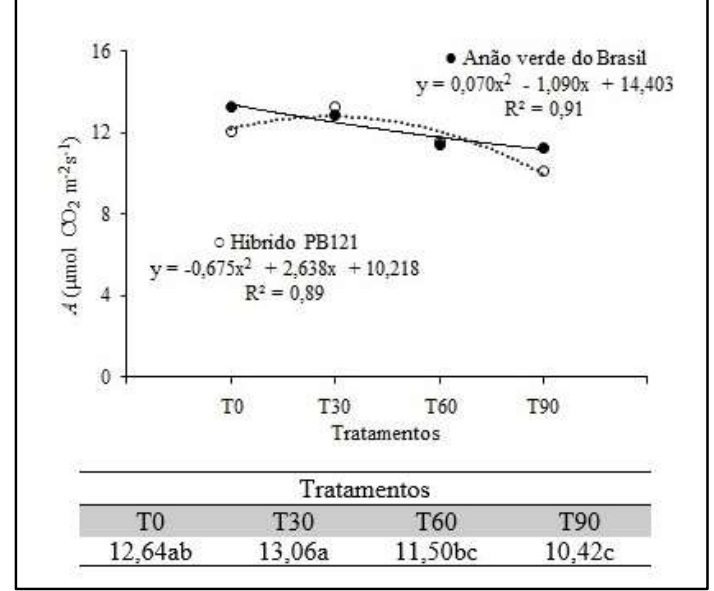

Figura 6: Análise de regressão da taxa de assimilação líquida de $\mathrm{CO}_{2}(\mathrm{~A})$ dos materiais genéticos híbrido PB121 e anão verde do Brasil, em quatro níveis de desfolha com suas funções de regressão e respectivas médias. Médias com a mesma letra não diferem entre si pelo teste Student- Newman- Keuls a $5 \%$ de probabilidade.

A taxa de assimilação líquida de $\mathrm{CO}_{2}(A)$, não foi afetada nos genótipos do coqueiro que sofrerem redução de até $60 \%$ da área foliar quarenta dias após a desfolha (Figura 6). Por outro lado, mudas com desfolhamento de $90 \%$ (T90), sofreram decréscimos de 17,6\% nesta variável em relação ao controle, indicando que aquela variável de troca gasosa é alterada pelos maiores níveis de desfolhamento sofrido pelos materiais analisados.

\section{DISCUSSÃO}

A redução de área foliar em uma planta pode resultar na produção de novos órgãos vegetais e na emissão de novas folhas, ou ainda no aperfeiçoamento das habilidades fotossintéticas das partes 
remanescentes, realocando recursos de outros órgãos com o intuito de remediar este déficit de biomassa. São os conhecidos efeitos de compensação (CRUZ-CASTILLO et al., 2010; BARRY et al., 2013)

A compensação se refere a diversas respostas fisiológicas que permitem que as plantas aumentem as taxas de crescimento ou a produção de sementes para compensar as perdas na biomassa ou na aptidão reprodutiva após a remoção do material vegetal (WIRF, 2006). No entanto, as partes remanescentes, em geral, não conseguem realizar, pelo menos a curto prazo, o efeito compensatório deste dano (BOEGE, 2005). A perda da biomassa reduz a taxa fotossintética, diminuindo recursos disponíveis para as plantas, afetando seu desempenho (STEETS et al., 2006; NARBONA et al., 2010; WANG et al., 2016).

O limite de desfolha que uma espécie de planta pode suportar, muitas vezes varia com a intensidade de desfolhação (HONKANEN et al., 1994; MARQUIS, 1984). Algumas espécies parecem ser capazes de compensar altos níveis de desfolhamento, enquanto, outras suportam menor dano (BROUGHTON, 2003; GADD et al., 2001). Estudos realizados por Ziems et al. (2006), em diferentes culturas, indicaram que as reduções de área foliar não afetaram as taxas de assimilação líquida de $\mathrm{CO}_{2}$ das partes remanescentes dos folíolos injuriados.

Este estudo sugere que os maiores danos provocados pelo desfolhamento foram compensados pelo aumento na taxa de transpiração (E) na variedade anão verde do Brasil, pois, esta variável tem relação direta com a taxa de assimilação líquida de $\mathrm{CO}_{2}$, o que está relacionado à maior concentração de gás carbônico no mesófilo foliar, resultante das alterações na condutância estomática das plantas (Figura 5). O aumento verificado na taxa de transpiração (E) da variedade anão verde do Brasil, evidencia a incapacidade dessa variedade em absorver água suficiente para repor aquela consumida no processo transpiratório, conforme também já foi evidenciado em estudos anteriores (SILVA et al., 2015).

Sugerimos que a menor resistência estomática aos processos difusivos de trocas gasosas na variedade anão verde do Brasil, resultou na menor eficiência instantânea do uso da água, o que provavelmente refletiu nos resultados menos expressivos das variáveis biométricas e na menor produção de biomassa vegetal (Figura 3), o que ficou evidente pela inabilidade de recuperação da área foliar após o dano provocado pelo desfolhamento quando comparado ao híbrido PB121 (Figura 4).

A severa desfolha reduz a oferta de carboidratos das plantas, ocorrendo em seguida, alta demanda dos mesmos (SRISOOK et al., 2015). Assim, acredita-se que algo semelhante tenha ocorrido na variedade anão verde do Brasil em que o requerimento energético para o crescimento vegetal não foi atendido nas condições de estresse.

Em adição, a maior eficiência de carboxilação, não foi suficiente para garantir maior produção de trioses fosfatadas requeridas nas etapas de crescimento na variedade anão verde do Brasil. Assim, inferimos que nesta variedade, as etapas de redução de $\mathrm{CO}_{2}$ foram inviabilizadas, possivelmente, pela menor disponibilidade hídrica no tecido vegetal.

A água participa ativamente nas etapas metabólicas de crescimento e de desenvolvimento vegetal, tendo em vista que muitas enzimas como as expansinas, por exemplo, atuam em meio hídrico (GONÇALVES 
et al., 2018). De modo geral, plantas C3 apresentam relação da eficiência instantânea do uso da água na ordem de $\mathrm{CO}_{2} / 400 \mathrm{mmol} \mathrm{H}_{2} \mathrm{O}$ (TAIZ et al., 2013). Sugerimos a partir dos resultados encontrados neste estudo, que esta relação na variedade anão verde do Brasil foi consideravelmente aumentada com reflexos negativos sobre recuperação da AF do vegetal (Figura 2).

Tinoco (2016), estudando a resposta fisiológica de híbridos interespecífico da palma de óleo (Elaeis guineensis Jacq. x Elaeis oleifera [Kunth, Cortés) mostrou que a injúria artificial com tesoura e natural por lagartas de $B$. sophorae não resultou em efeitos no processo fisiológico das folhas remanescentes em mudas desta espécie, justificando esta resposta com os prováveis mecanismos compensatórios do vegetal evitando interromper seus processos fisiológicos.

Como o processo fotossintético ocorre principalmente nas folhas e o material genético híbrido PB121 apresentou maior área foliar, (Figura 2) logo, pode ter havido maior disponibilidade de fotoassimilados neste material genético e, o que justifica o maior crescimento, o qual ficou confirmado pelos maiores incrementos na altura (Figura 1). Mudas que apresentam maior massa da parte aérea, têm maior área foliar, o que facilita o estabelecimento inicial das mudas no campo.

Faria et al. (2002) avaliaram o comportamento de cinco genótipos de anões e híbridos do coqueiro e notaram que o híbrido (AAG x GOA) e o anão vermelho de Gramame (AVG) apresentaram, respectivamente, maiores e menores valores para as características: Número de folhas, altura aos 30, 60 e 90 dias após o plantio no viveiro, circunferência do coletor e porcentagem de mudas aptas ao viveiro. Corroborando a proeminência do material vegetal híbrido PB121, neste trabalho. Para Genty et al. (1978), apenas uma lagarta desfolhadora de mudas das palmeiras, alimenta-se de até $800 \mathrm{~cm}^{2}$ durante todo o ciclo larval. No entanto, Tinoco (2016), observou em laboratório, durante 43 dias, que lagartas de $O$. envirae, consumiram $286 \mathrm{~cm}^{2}$ de área foliar em palma de óleo.

Partindo desse estudo, nossos dados sugerem que o híbrido PB121, suporta até 3 lagartas/muda, o que corresponde a $30 \%$ da desfolha, tendo este dano restaurado pela emissão de $4.000 \mathrm{~cm}^{2}$ de $\mathrm{AF}$ em resposta ao estresse. Assim, T30 representa o limite máximo de desfolhamento que garante o posterior restabelecimento da AF. Ressalta-se ainda que àquele número de lagartas configura como indicativo biológico para aplicação de inseticidas no viveiro, ou nível crítico para a muda. Nesse sentido fica evidente que a recuperação da produção de biomassa vegetal no híbrido PB121 (Figura 3), foi eficientemente atingida tendo em vista a sobre expressão na emissão da AF em resposta à injúria ao tecido foliar, o que garantiu, assim, a manutenção dos processos fotossintéticos fundamentais ao desenvolvimento vegetal.

\section{CONCLUSÕES}

Mudas do coqueiro anão verde do Brasil são mais sensíveis a desfolha em todos os níveis apresentados comparados ao genótipo híbrido PB121. O material genético híbrido PB121 suporta até 3 lagartas/muda causando desfolhamento, o que corresponde a 30\% de desfolha, sendo o indicativo biológico 
para tomadas de decisão de controle no viveiro. Os resultados deste estudo sugerem a investigação das alterações de amido e açúcares solúveis em estudos futuros.

\section{REFERÊNCIAS}

BARRY, K. M.; PINKARD, E. A.. Growth and photosynthetic responses following defoliation and bud removal in eucalypts. Forest Ecology and Management, v.293, p.9-16,

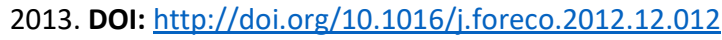

BOEGE, K.. Influence of plant ontogeny on compensation to leaf damage. American Journal of Botany, v.92, p.16321640, 2005. DOI: https://doi.org/10.3732/ajb.92.10.1632

BROUGHTON, S.. Effect of artificial defoliation on growth and biomass of Lantana camara L. (Verbenaceae). Plant Protection Quarterly, v.18, p.110-115, 2003. DOI: http://dx.doi.org/10.5902/1980509832082

CANTARELli, E. B.; COSTA, E. C.; PEZZUTTI, R.; OlIVEIRA, L. S.. Quantificação das perdas no desenvolvimento de Pinus taeda após o ataque de formigas cortadeiras. Ciência Florestal, v.18, n.1, p.39-45, 2008. DOI: http://dx.doi.org/10.5902/19805098509

CRUZ-CASTILLO, J. G.; WOOLLEY, D. J.; FARMIANI, F.. Effects of defoliation on fruit growth, carbohydrate reserves and subsequent flowering of 'Hayward' kiwifruit vines. Scientia Horticulturae, v.125, n4, p.537-539, 2010. DOI: https://doi.org/10.1016/j.scienta.2010.05.004

FARIA, W. S.; GAÍVA, H. N.; PEREIRA, W. E.. Comportamento de cinco genótipos do coqueiro (Cocos nucifera L.) na fase de germinação e de crescimento de mudas, sob diferentes sistemas de produção. Rev. Bras. Frutic., Jaboticabal, v.24, n.2, p.458-462, 2002. DOI: http://dx.doi.org/10.1590/S0100$\underline{29452002000200035}$

FAZOLIN, M.; ESTRELA, E. J. L. V.. Determinação do nível de dano econômico de Cerotoma tingomarianus Bechyné (Coleoptera: Chrysomelidae) em Phaseolus vulgaris L. CV. Pérola. Neotrop Entomol, v.33, n.1, p.631-637, 2004. DOI: http://dx.doi.org/10.1590/S1519-566X2004000500014

FERREIRA, J. M. S.. Manejo integrado de pragas do coqueiro. Ciência Agrícola, v.8, n.1, p.21-29, 2008.

FERREIRA, J. M. S.; TEODORO, A. V.; NEGRISOLI, A. S. J.; GUZZO, E. C.. Aspectos biológicos e manejo da Cochonilhatransparente Aspidiotus destructor e do Pulgão-preto Cerataphis Lataniae em coqueiro. Brasília: Embrapa, 2015.

FONTES, H. R.. Caracterização do quadro atual e principais ameaças à produção de coco seco no nordeste do Brasil. Brasília: Embrapa Tabuleiro Costeiros, 2010.

GADD, M. E.; YOUNG, T. P.; PALMER, T. M.. Effects of simulated shoot and leaf herbivory on vegetative growth and plant defense in Acacia drepanolobium. Oikos, v.92, p.515-521, 2001. DOI: https://doi.org/10.1034/j.16000706.2001.920312.x
GENTY, P.; CHENON, R. D.; MORIN, J. P.; KORYTKOWSKI, C. A.. Las plagas de la palma aceitera en América Latina. Oléagineux, v.33, p.324-594, 1978.

GONÇALVES, L. P.. Transcriptoma em condição de déficit hídrico e caracterização de expansinas em Citrus sinensis L. Osb. Tese. (Doutorado em Genética e Biologia Molecular) Universidade Estadual de Santa Cruz, Ilhéus, 2018.

HONKANEN, T.; HAUKIOJA, E.; SUOMELA, J.. Effects of simulated defoliation and debudding on needle and shoot growth in Scots pine (Pinus sylvestris): implications of plant source-sink relationships for plant-herbivore studies. 1994.

JUHÁSZ, A. C. P.. Desafios fitossanitários para a produção de soja: Defesa vegetal e sustentabilidade do agronegócio. Informe Agropecuário, Belo Horizonte, v.34, p.66-75, 2013.

KULMAN, H. M.. Effects of insect defoliation on growth and mortality of trees. Anual Review of Entomology, v.16, p.289-324, 1971. DOI:

http://doi.org/10.1146/annurev.en.16.010171.001445

LIMA JUNIOR, S. I.; BERTONCELLO, F. T.; MELO, P. E.; DEGRANDE, E. P.; KODAMA, C.. Desfolha artificial simulando danos de pragas na cultura do girassol (Helianthus annuus L., Asteraceae). Rev. Ceres, Viçosa, v.57, n.1, p.023-027, 2010. DOI: http://dx.doi.org/10.1590/S0034-737X2010000100005

LINS, P. M. P.; VIÉGAS, I. J. M.. Adubação do coqueiro no Pará. Circular técnica. Manaus: Embrapa Amazônia Oriental, 2008.

LOIOLA, C. M.; ARAGÃO, W. M.; PEDROSO, G. T.; ALVES, A. S.; ARAGÃO, F. B.. Seleção de cultivares do coqueiro com menor porte. Brasília: Embrapa Tabuleiros Costeiros, 2005.

MARQUIS, R. J.. Leaf herbivores decrease fitness of a tropical plant. Science, v.226, n.4674, p.537-539, 1984. DOI: http://doi.org/10.1126/science.226.4674.537

MONTEIRO, J. E. B. A.; SENTELHAS, P. C.; CHAVEGATO, E. J.; GUISELINI, C.; SANTIAGO, A. V.; PRELA, A.. Estimação da área foliar do algodoeiro por meio de dimensões e massa das folhas. Bragantina, Campinas, v.64, n.1, p.12-24, 2005. DOI: http://dx.doi.org/10.1590/S0006-87052005000100002

NARBONA, E.; DIRZO, R.. Experimental defoliation affects male but not female reproductive performance of the tropical monoecious plant Croton suberosus (Euphorbiaceae). Annals of Botany, v.106, n.2, p.359-369, 2010. DOI: https://doi.org/10.1093/aob/mcq117

SILVA, F. G.; DUTRA, W. F. DUTRA, A. F. DE OLIVEIRA, I. M.; FILGUEIRAS, L. M. B.; MELO, A. S.. Trocas gasosas e fluorescência da clorofila em plantas de berinjela sob lâminas de irrigação. Revista Brasileira de Engenharia Agrícola e Ambiental-Agriambi, v.19, n.10, p.946-952, 2015. 
DOI: http://dx.doi.org/10.1590/1807-

\section{9/agriambi.v19n10p946-952}

SRISOOK, W.; LIM, C.; OH, E. U.; YI, K.; KIM, S.; PARK, K. S.; SONG, K. J.. Effect of Artificial Defoliation on Cane Regrowth and Fruit Development in 'Jecy Gold' Kiwifruit. Hort.

Environ. Biotechnol., v.56, n.1, p.22-26, 2015.

DOI: http://doi.org/10.1007/s13580-015-0119-9

STEETS, J. A.; HAMRICK, J. L.; ASHMAN, T. L.. Consequences of vegetative herbivory for maintenance of intermediate outcrossing in an annual plant. Ecology Ecological Society of America, v.87, p.2717-2727, 2006. DOI:

https://doi.org/10.1890/00129658(2006)87[2717:COVHFM]2.0.CO;2

TAIZ, L.; ZEIGER, E.. Fisiologia vegetal. 5 ed. Porto Alegre: Artmed, 2013.

TINOCO, R. S.. Determinação do nível de dano econômico para Opsiphanes invirae Hubner, 1808 (Lepdoptera: nyphalidae) em palma de óleo. Tese. (Doutorado em
Agronomia) - Universidade Estadual Paulista, São Paulo, 2016.

WANG, L. L.; WANG, B.; SHANG, N.; LIU, W. Z.. Effects of experimental defoliation on resource allocation using integrated physiological units in the andromonoecious Camptotheca acuminata. South African Journal of Botany, v.104, p.47-54, 2016. DOI:

https://doi.org/10.1016/j.sajb.2015.11.007

WIRF, L. A.. The effect of manual defoliation and Macaria pallidata (Geometridae) herbivory on Mimosa pigra: Implications for biological control. Biological Control, v.37, p.346-353, 2006.

DOI: http://doi.org/10.1016/j.biocontrol.2005.12.011

ZIEMS, J. R.; ZECHMANN, B. J.; HOBACK, W. W.; WALLACE, J. C.; MADSEN, R. A.; HUNT, T. E.; HIGLEY, L. G.. Yield response of indeterminate potato (Solanum tuberosum L.) to simulated insect defoliation. Agr. Journal, v.98, n.6, p.14351441, 2006. DOI: http://doi.org/10.2134/agronj2005.0245

A CBPC - Companhia Brasileira de Produção Científica (CNPJ: 11.221.422/0001-03) detém os direitos materiais desta publicação. Os direitos referem-se à publicação do trabalho em qualquer parte do mundo, incluindo os direitos às renovações, expansões e disseminações da contribuição, bem como outros direitos subsidiários. Todos os trabalhos publicados eletronicamente poderão posteriormente ser publicados em coletâneas impressas sob coordenação da Sustenere Publishing, da Companhia Brasileira de Produção Científica e seus parceiros autorizados. Os (as) autores (as) preservam os direitos autorais, mas não têm permissão para a publicação da contribuição em outro meio, impresso ou digital, em português ou em tradução. 